\title{
The role of shrinkage reducing admixtures and supplementary cementitious materials in volume stability and strength development
}

\author{
Ioanna Papayianni ${ }^{1, *}$, Fotini Kesikidou ${ }^{1}$, and Philip Henes Alt $^{1}$ \\ ${ }^{1}$ Laboratory of Building Materials, School of Civil Engineering, Aristotle University of Thessaloniki
}

\begin{abstract}
Shrinkage is one of the main reasons for mortar and concrete failures like curling, crack formation and de-bonding. It is a complex phenomenon due to many factors involved, such as the type and amount of cement, water to binder ratio, binder to aggregates ratio and the type and granulometry of the aggregates, relative humidity, air temperature and the temperature of concrete. To reduce this phenomenon, Shrinkage Reducing Admixtures (SRAs) have been studied over the last 30 years. On the other hand, investigation in the field of Supplementary Cementitious Materials (SCMs) has indicated that their use in concrete may improve its volume stability depending on their percentage and the type of the material. In this paper, the addition of a Shrinkage Reducing Admixture and Supplementary Cementitious Materials like ladle furnace slag, calcareous fly ash and limestone filler, were investigated. Their influence, separately and in combination, in volume stability and strength development of cement mortars was identified. Capillary absorption and open porosity were also determined.
\end{abstract}

\section{Introduction}

Shrinkage is one of the main reasons for mortar and concrete failures like curling, crack formation and debonding. The loss of moisture from fresh concrete results in a reduction in volume. If the shrinkage movement is opposed by some external or internal restraint, stresses will develop. When the stress exceeds the tensile capacity of the concrete, cracks are formed, causing an increase in surface permeability and promoting concrete deterioration and corrosion of embedded reinforcement (1) (2) (3) (4).

Shrinkage is a complex phenomenon due to the many factors involved, such as the type and amount of cement, water to binder ratio, binder to aggregates ratio and the type and granulometry of the aggregates, relative humidity, air temperature and the temperature of concrete. There are several types of shrinkage. Plastic shrinkage, which occurs when fresh concrete loses moisture, autogenous shrinkage due to chemical reactions during the hydration process, thermal shrinkage and finally drying shrinkage, which is caused by the movement and loss of water (3) (5) (6).

To reduce this phenomenon, Shrinkage Reducing Admixtures (SRAs) have been studied over the last 30 years. They are designed to decrease drying shrinkage by reducing the surface tension that is developed when moisture is lost from very small pores during the drying of concrete (7) (8). Research has shown around 50 to $60 \%$ shrinkage reduction at 28 days and around 40 to $50 \%$ at the age of 90 days, with the use of SRAs.
However, loss of compressive strength up to $15 \%$ has also been reported (9) (10).

On the other hand, investigation in the field of Supplementary Cementitious Materials (SCMs) has indicated that their use in concrete may improve its volume stability depending on their percentage and the type of the material (11) (12). The addition of SCMs generally increases the pore refinement of the concrete and creates smaller pores in the matrix, causing the reduction of shrinkage (5) (13) (14) (15). Furthermore, the autogenous shrinkage is said to be reduced at an early age due to the slow hydration reaction of SCMs (16).

In this paper, the addition of a Shrinkage Reducing Admixture and Supplementary Cementitious Materials like ladle furnace slag, calcareous fly ash and limestone filler, were investigated. Their influence in volume stability and strength development of cement mortars was identified. Capillary absorption and open porosity were also determined.

\section{Experimental}

\subsection{Mixing}

Twelve mortar mixes were produced, six of them with the addition of the SRA and six without. European Standard, EN196-1, was followed for the mixing procedure. Siliceous sand (0-4) $\mathrm{mm}$ was used as aggregate in a 1:3 binder: aggregate ratio. Chemical analysis of the binders is presented in Table 1 and composition of the mixtures in Table 2. 
Table 1. Chemical composition (\%w.t.), specific gravity and fineness of the binders.

\begin{tabular}{|c|c|c|c|c|}
\hline Binder & $\begin{array}{c}\text { CEM I } \\
42.5\end{array}$ & $\begin{array}{c}\text { CEM IV } \\
32.5 \\
\end{array}$ & LFS & Fly ash* \\
\hline $\mathrm{SiO}_{2}$ & 19.6 & 17.07 & 25.23 & 29.12 \\
\hline $\mathrm{Al}_{2} \mathrm{O}_{3}$ & 2.4 & 7.27 & 3.31 & 15.24 \\
\hline $\mathrm{FeO}_{3}$ & 8.11 & 2.7 & 3.14 & 6.59 \\
\hline $\mathrm{CaO}$ & 66.84 & 54.67 & 53.94 & 40.72 \\
\hline $\mathrm{MgO}$ & 3.91 & 2.34 & 5.26 & 4.73 \\
\hline $\mathrm{Na}_{2} \mathrm{O}$ & 0.57 & 0.48 & 0.22 & 0.8 \\
\hline $\mathrm{K}_{2} \mathrm{O}$ & 1.08 & 0.58 & 0.48 & 1.58 \\
\hline L.I. & 1.91 & 14.26 & 7.18 & 0.22 \\
\hline $\begin{array}{l}\text { Specific } \\
\text { Gravity } \\
\left(\mathrm{g} / \mathrm{cm}^{3}\right)\end{array}$ & 3.1 & & 2.65 & 2.28 \\
\hline $\begin{array}{l}\text { Particle } \\
\text { size } \\
\text { volume } \\
(\%)\end{array}$ & $\begin{array}{c}10-15 \mu \mathrm{m} \\
6-7 \%\end{array}$ & $\begin{array}{c}10-25 \mu \mathrm{m} \\
5-6 \%\end{array}$ & $\begin{array}{c}60-70 \mu \mathrm{m} \\
>5 \%\end{array}$ & $\begin{array}{c}\text { retained } \\
\text { on } 45 \mu \mathrm{m} \\
\text { sieve } \\
43 \%\end{array}$ \\
\hline
\end{tabular}

$* \mathrm{CaOH}_{\text {free }}=10.8 \%$

Table 2. Composition of the mortars

\begin{tabular}{|c|c|c|c|c|c|}
\hline \multirow[b]{2}{*}{ Mix } & \multicolumn{2}{|c|}{ Binder } & \multirow[b]{2}{*}{ W/B } & \multirow{2}{*}{$\begin{array}{c}\text { Worka } \\
\text { bility } \\
(\mathrm{cm})\end{array}$} & \multirow[b]{2}{*}{ Remarks } \\
\hline & $\begin{array}{c}\text { Ceme } \\
\text { nt }\end{array}$ & $\mathrm{SCM}$ & & & \\
\hline I 42.5 & 1 & - & 0.54 & 15 & $\begin{array}{c}\text { Cement } \\
\text { I } 42.5\end{array}$ \\
\hline $\mathrm{I} 42.5-\mathrm{S}$ & 1 & - & 0.54 & 16 & $1 \%$ SRA \\
\hline $\mathrm{S}$ & 0.8 & 0.2 & 0.58 & 15 & $\begin{array}{c}20 \% \text { re- } \\
\text { placement } \\
\text { of cement } \\
\text { with Ladle } \\
\text { Furnace } \\
\text { Slag (S) }\end{array}$ \\
\hline S-S & 0.8 & 0.2 & 0.58 & 17 & $1 \%$ SRA \\
\hline SF & 0.7 & $\begin{array}{c}0.2 / \\
0.1\end{array}$ & 0.54 & 15 & $\begin{array}{c}20 \%(\mathrm{~S}) \\
10 \% \\
\text { limestone } \\
\text { filler }(\mathrm{F})\end{array}$ \\
\hline SF-S & 0.7 & $\begin{array}{l}0.2 / \\
0.1\end{array}$ & 0.54 & 16 & $1 \%$ SRA \\
\hline FA & 0.7 & 0.3 & 0.64 & 15.7 & $\begin{array}{l}30 \% \text { Fly } \\
\text { Ash (FA) }\end{array}$ \\
\hline FA-S & 0.7 & 0.3 & 0.64 & 16 & $1 \%$ SRA \\
\hline FAS & 0.5 & $\begin{array}{l}0.3 / \\
0.2\end{array}$ & 0.56 & 16 & $\begin{array}{c}30 \%(\mathrm{FA}), \\
20 \%(\mathrm{~S})\end{array}$ \\
\hline FAS-S & 1.5 & $\begin{array}{l}0.3 / \\
0.3\end{array}$ & 0.56 & 16.5 & $1 \%$ SRA \\
\hline IV 32.5 & 1 & - & 0.54 & 15 & $\begin{array}{l}\text { Cement } \\
\text { IV } 32.5\end{array}$ \\
\hline IV $32.5-\mathrm{S}$ & 1 & - & 0.54 & 15 & $1 \%$ SRA \\
\hline
\end{tabular}

Water was added in order to achieve workability of $16 \pm 1 \mathrm{~cm}$, according to EN 1015-3. All mixes marking with $-\mathrm{S}$ indicate the addition of the SRA ( $1 \%$ by mass of the binder). Water to binder ratio was around $0.54-0.58$, with the exception of the mixture with fly ash (0.64). The use of SRA seems to improve slightly the workability of the mortars. No superplasticizer was used in any of the mortars, in order to reduce the influence of other mechanisms in the hydration process. Prismatic specimens $(40 \times 40 \times 160) \mathrm{mm}$ were produced and tested at the ages of 7 and 28 days. After demoulding, the specimens were kept in a climate chamber with $20^{\circ} \mathrm{C}$ and $\mathrm{RH}>95 \%$.

Table 3. Density of the mortars in the fresh and hardened state

\begin{tabular}{|c|c|c|}
\hline Mixture & $\begin{array}{c}\rho_{\text {fresh }} \\
\left(\mathrm{g} / \mathrm{cm}^{3}\right)\end{array}$ & $\begin{array}{c}\rho_{\text {hard }} \\
\left(\mathrm{g} / \mathrm{cm}^{3}\right) \\
7 \text { days }\end{array}$ \\
\hline I 42.5 & 2.24 & 2.13 \\
\hline $\mathrm{I} 42.5 \mathrm{~S}$ & 2.26 & 2.18 \\
\hline $\mathrm{S}$ & 2.3 & 2.19 \\
\hline S-S & 2.18 & 2.16 \\
\hline SF & 2.45 & 2.13 \\
\hline SF-S & 2.24 & 2.11 \\
\hline IV 32.5 & 2.3 & 2.19 \\
\hline $\begin{array}{c}\text { IV } \\
32.5-\mathrm{S} \\
\end{array}$ & 2.23 & 2.16 \\
\hline FA & 2.26 & 2.1 \\
\hline FA-S & 2.21 & 2.1 \\
\hline FAS & 2.24 & 2.09 \\
\hline FAS-S & 2.23 & 2.08 \\
\hline
\end{tabular}

From the measured density of the fresh mortar (Table 3 ), it seems that there is a weight loss from $0.4 \%$ to $8 \%$, comparing the mixtures with and without the SRA. The smallest loss was observed for the mortar with fly ash and ladle furnace slag (FAS) and the highest for the combination of ladle furnace slag and limestone filler (SF). Different behaviour was shown by the mix with I42.5 cement, as it appears to gain weight when the SRA was added. Similar results were noted and for the hardened state density.

\subsection{Mechanical characteristics}

The mortars were tested under flexural and compressive strength (EN 1015-11) and dynamic modulus of elasticity was determined at the ages of 7 and 28 days. According to Table 4, it seems that mortar mixes with SRA exhibited a very slight difference in flexural strength at $7-\mathrm{d}$ and $28-\mathrm{d}$ age (from $3 \%$ to $10 \%$ ) increase or decrease. In the case of the respective compressive strength (Table 5) a small drop in strength (from $6 \%$ to $18 \%$ ) is observed in mixtures with SRA apart from mixtures containing $20 \%$ ladle furnace slag, which 
showed a decrease in strength up to $40 \%$. Values taken for $E_{\text {dyn }}$ (Table 6), measured by ultrasonic pulse velocity, generally follow those of compressive strength. However, they are not so representative because they are significantly influenced by the moisture content of mortar specimens.

It could be said that the mechanical characteristics are influenced to a low degree which is more obvious in compressive than in flexural strength. There is also a small drop in fresh density measurements except for CEM I42.5 mortar that showed a slight increase. Similar results were noted for the hardened mortars' density.

Table 4. Flexural strength at 7 and 28 days.

\begin{tabular}{|c|c|c|}
\hline \multirow{2}{*}{ Mix } & \multicolumn{2}{|c|}{$\sigma_{\mathrm{K}}(\mathrm{MPa})$} \\
\cline { 2 - 3 } & 7 days & 28 days \\
\hline I42.5 & 3.43 & 4.00 \\
\hline I42.5-S & 3.55 & 4.27 \\
\hline S & 3.67 & 4.35 \\
\hline S-S & 3.80 & 3.77 \\
\hline SF & 3.17 & 4.72 \\
\hline SF-S & 2.79 & 4.49 \\
\hline FA & 3.14 & 4.65 \\
\hline FA-S & 2.83 & 5.03 \\
\hline FAS & 3.34 & 4.22 \\
\hline FAS-S & 2.81 & 4.60 \\
\hline IV32.5 & 4.08 & 4.95 \\
\hline IV32.5-S & 3.32 & 4.68 \\
\hline
\end{tabular}

Table 5. Compressive strength at 7 and 28 days.

\begin{tabular}{|c|c|c|}
\hline \multirow{2}{*}{ Mix } & \multicolumn{2}{|c|}{$\sigma_{\Theta}(\mathrm{MPa})$} \\
\cline { 2 - 3 } & 7 days & 28 days \\
\hline I42.5 & 37.71 & 45.98 \\
\hline I42.5-S & 35.46 & 40.57 \\
\hline S & 39.27 & 45.32 \\
\hline S-S & 22.27 & 31.61 \\
\hline SF & 25.01 & 29.07 \\
\hline SF-S & 21.95 & 26.28 \\
\hline FA & 22.10 & 31.20 \\
\hline FA-S & 19.83 & 28.74 \\
\hline FAS & 21.50 & 26.58 \\
\hline FAS-S & 16.96 & 26.87 \\
\hline IV32.5 & 35.30 & 33.29 \\
\hline IV32.5-S & 28.83 & 34.79 \\
\hline
\end{tabular}

Table 6. Dynamic modulus of elasticity at 7 and 28 days.

\begin{tabular}{|c|c|c|}
\hline \multirow{2}{*}{ Mix } & \multicolumn{2}{|c|}{$E_{\text {dyn }}(\mathrm{GPa})$} \\
\cline { 2 - 3 } & 7 days & 28 days \\
\hline I42.5 & 32.31 & 35.86 \\
\hline I42.5-S & 36.14 & 36.05 \\
\hline S & 35.42 & 34.92 \\
\hline S-S & 31.49 & 32.09 \\
\hline SF & 28.89 & 34.62 \\
\hline SF-S & 31.41 & 35.79 \\
\hline FA & 26.82 & 34.30 \\
\hline FA-S & 23.63 & 34.40 \\
\hline FAS & 27.83 & 33.98 \\
\hline FAS-S & 25.09 & 32.30 \\
\hline IV32.5 & 32.36 & 38.66 \\
\hline IV32.5-S & 28.47 & 36.71 \\
\hline
\end{tabular}

\subsection{Physical characteristics}

In order to test the ability of the materials in shrinkage conditions, volume stability was measured for 28 days. During this period, the specimens were kept in a climate chamber with $20^{\circ} \mathrm{C}$ and $60 \%$ of relative humidity. The measurements are shown in Figures 1-6. Capillary absorption, according to EN 1015-18, is shown in Figures 7-12. Finally, open porosity was measured at the age of 28 days according to the RILEM CPC11.3 method and is presented in Table 7.

Regarding volume stability measurements in Figure 1 to Figure 6, it could be said that the SRA addition has a clear positive effect in reducing shrinkage deformations in the case of mortars with CEM I42.5 and CEM IV32.5. In the mortars with the SCMs the effect is neutral (as shown in Figure 3) or a little different in comparison with the respective mortars without SRA. As shown in Figure 5, mortars with FA exhibited a significant expansion with the addition of SRA. It is worth mentioning that mortars with SCMs even that with blended type CEM IV32.5 showed lower deformations (better volume stability) in comparison to mortar with CEM I42.5, although the water/cementitious ratio was in these mortars higher as shown in Table 2.

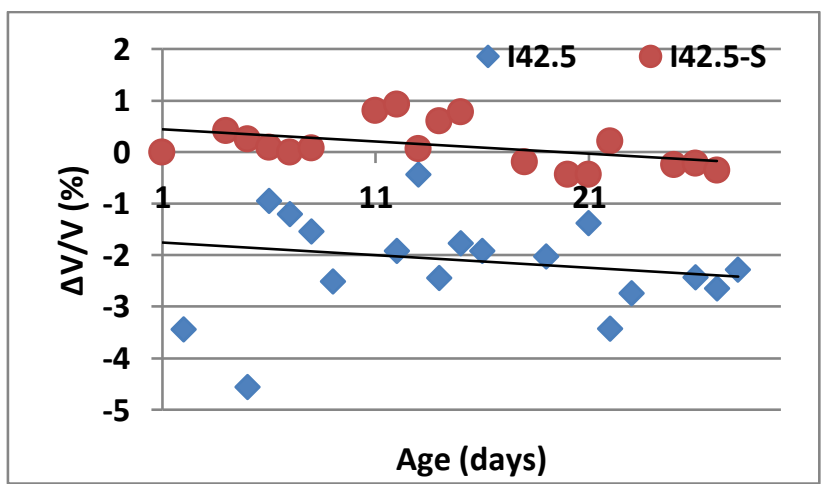

Fig. 1. Volume stability of I42.5 and I42.5-S mixtures 


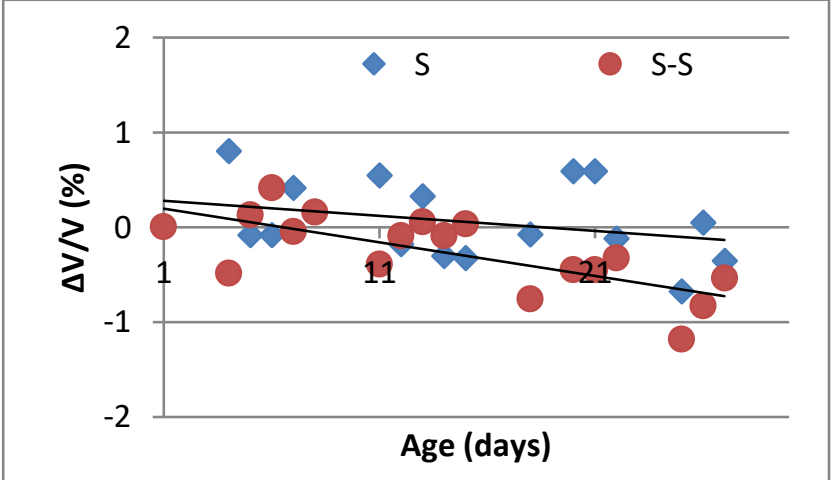

Fig.2. Volume stability of S and S-S mixtures

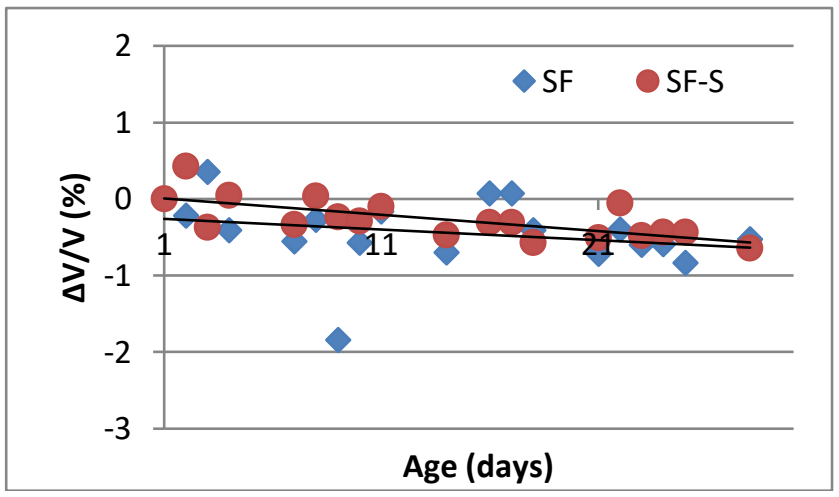

Fig.3. Volume stability of SF and SF-S mixtures

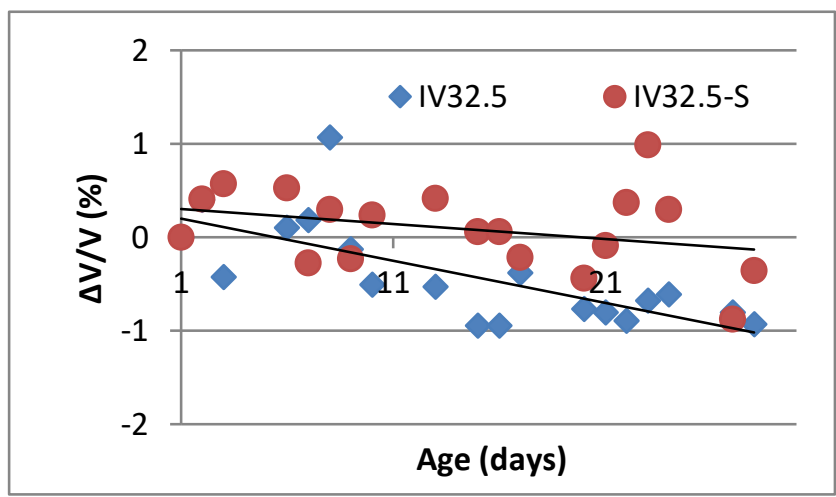

Fig.4. Volume stability of IV32.5 and IV32.5-S mixtures

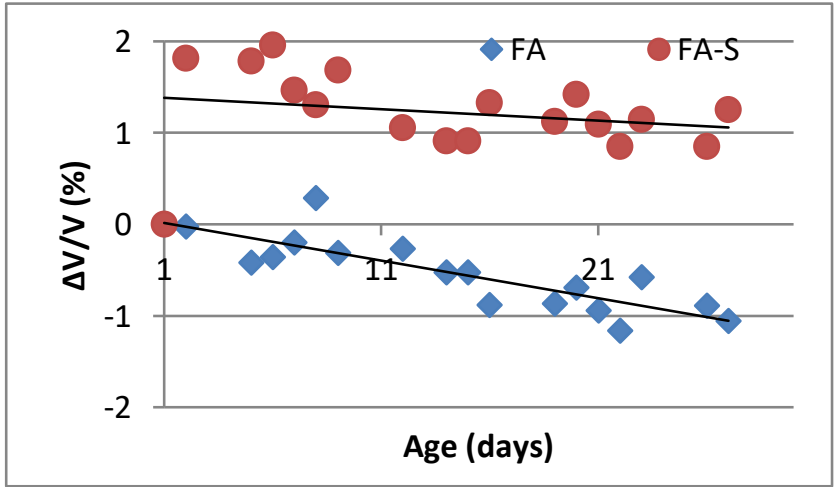

Fig.5. Volume stability of FA and FA-S mixtures

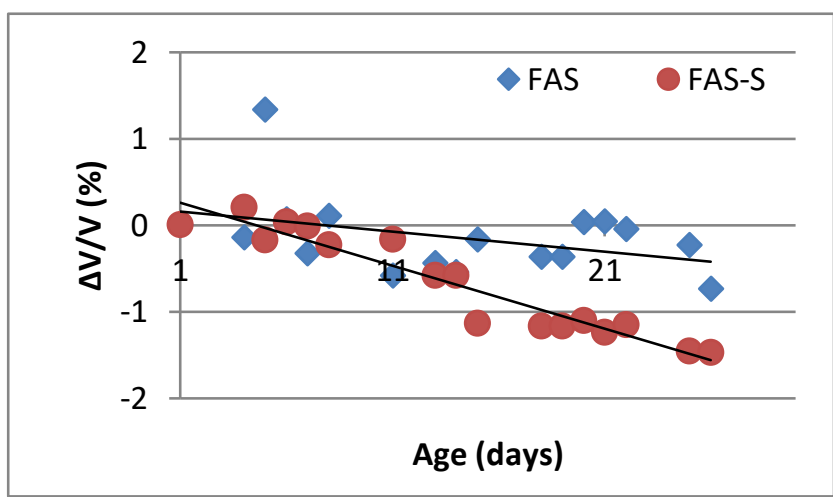

Fig.6. Volume stability of FAS and FAS-S mixtures

Concerning the porosity measurements of the mortar specimens, in most cases there is an increase of 28-d porosity, with the addition of SRA, apart from mortars with CEM I42.5 and those with SF (ladle slag + filler). Therefore, it could be said that porosity or other included voids open to surface are not reduced with addition of SRA.

Table 7. Open porosity at 28 days.

\begin{tabular}{|c|c|}
\hline Mix & $\begin{array}{c}\text { Porosity } \\
(\%)\end{array}$ \\
\hline I42.5 & 6.12 \\
\hline I42.5S & 5.19 \\
\hline S & 4.88 \\
\hline S-S & 7.5 \\
\hline SF & 7.27 \\
\hline SF-S & 6.65 \\
\hline FA & 7.3 \\
\hline FA-S & 6.63 \\
\hline FAS & 6.82 \\
\hline FAS-S & 7.25 \\
\hline IV32.5 & 5.51 \\
\hline IV32.5- & 6.15 \\
\hline S &
\end{tabular}

Capillary absorption of mortars with SRA (Figures 7 to 12) showed that it is similar to the respective mortar without SRA or a little lower. In the case of S -S mortar there is a slight increase of absorption in mortar with SRA. It means that the continuity of pores somehow is not favored or is blocked with the addition of SRA. 


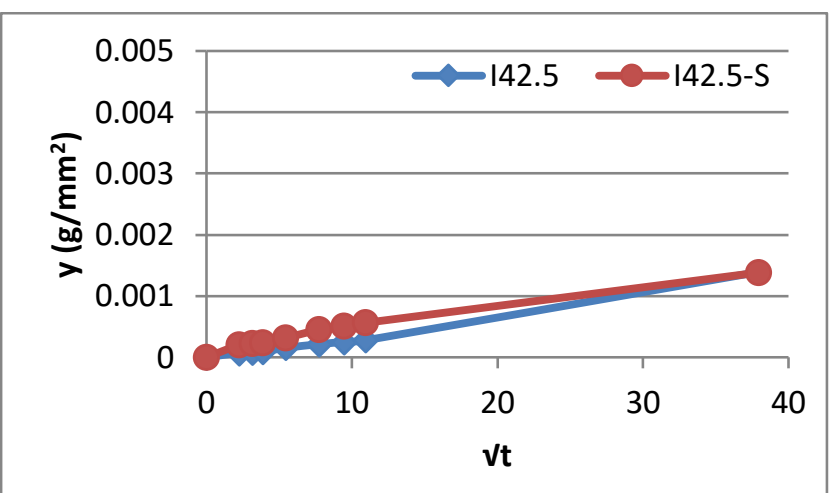

Fig.7. Capillary absorption of I42.5 and I42.5-S.

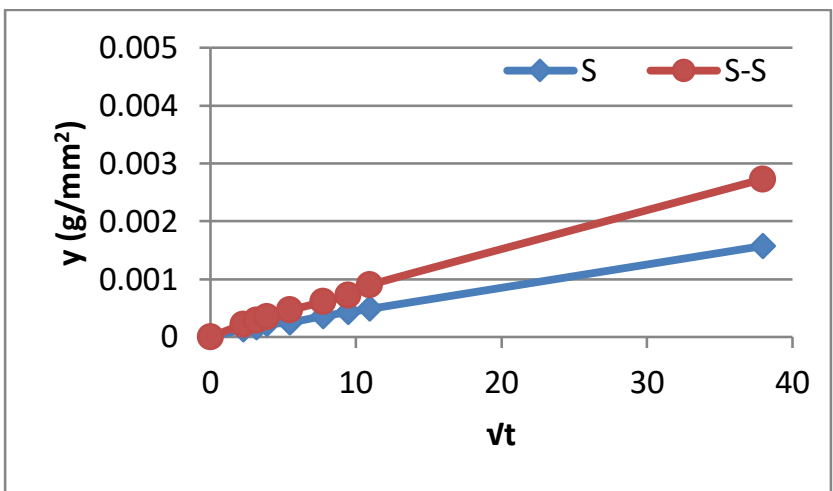

Fig.8. Capillary absorption of S and S-S.

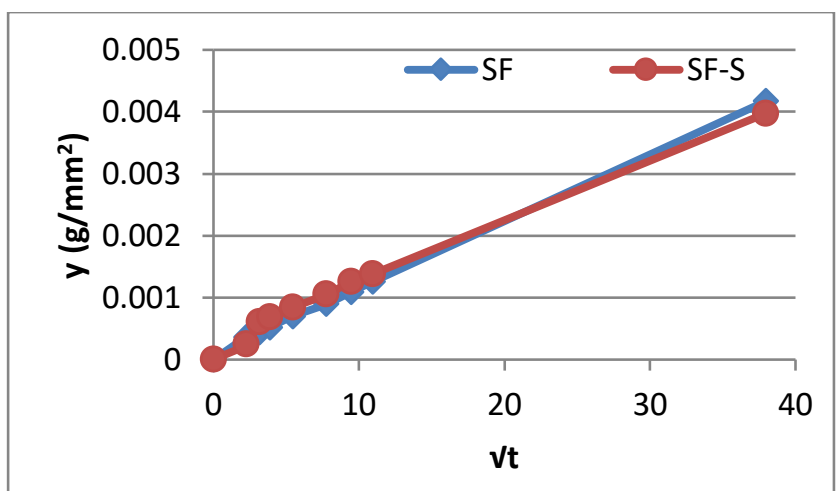

Fig.9. Capillary absorption of SF and SF-S.

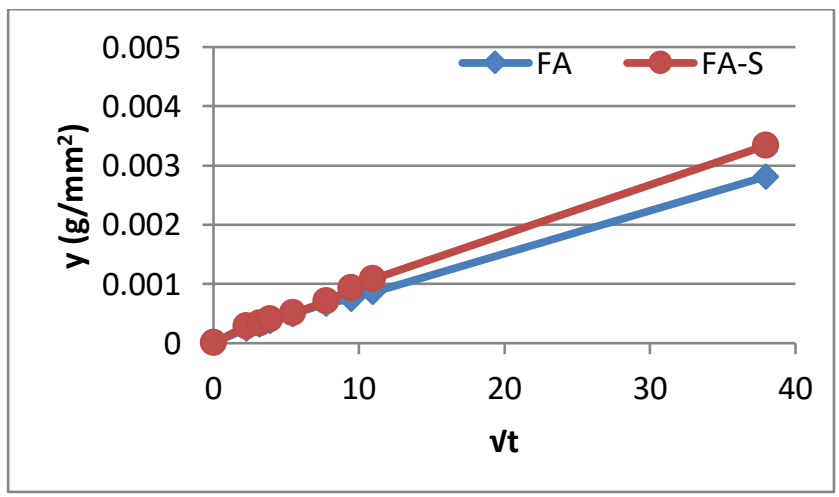

Fig.10. Capillary absorption of FA and FA-S.

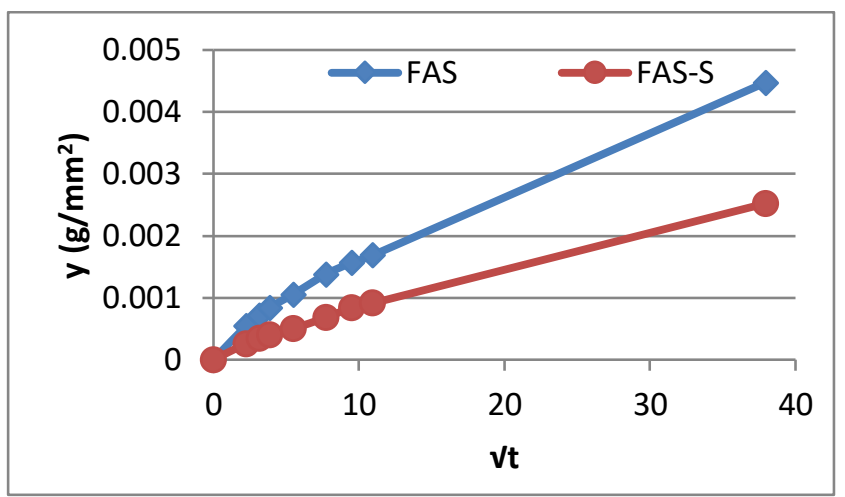

Fig.11. Capillary absorption of FAS and FAS-S.

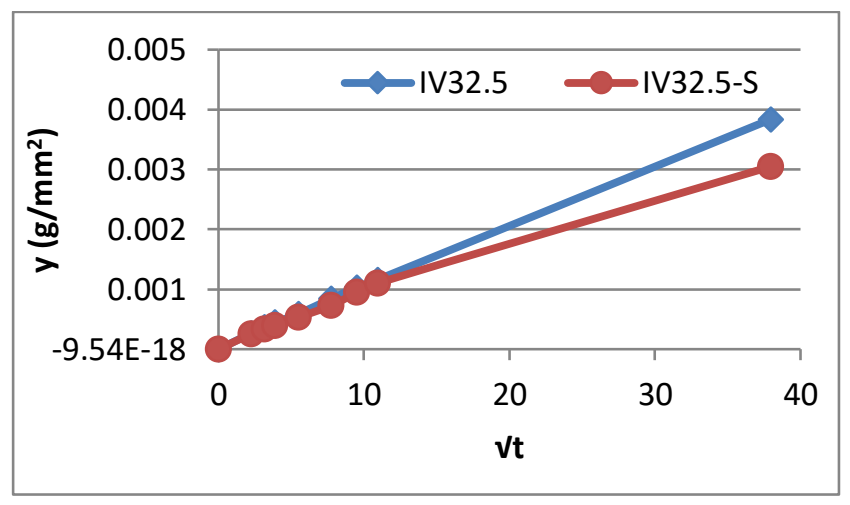

Fig.12. Capillary absorption of IV 32.5 and IV32.5-S.

\section{Conclusions}

The effectiveness of SRA seems to be influenced by the binders of the mortars. The performance of it is clearly positive in mortars with CEM I42.5, but in the case of use of $\operatorname{SCM}(\mathrm{s})$ the reduction in shrinkage deformations is dependable on the binding system and further investigation is needed to describe the SRA performance with different type $\mathrm{SCM}(\mathrm{s})$ in the system. It should be mentioned that the $\mathrm{SCM}(\mathrm{s})$ addition itself reduces shrinkage deformation.

A slight but clear decrease in compressive strength was presented by all mortars with SRA while flexural strength was unchanged. It could be also said that a slight mitigation of capillary elevation was observed with addition of SRA. It must be said that the test results concern the addition in all mortar mixtures of the same dosage of SRA ( $1 \%$ by mass of the binder). Investigation about the optimization of the required dosage to each binding system has not been made.

\section{References}

1. F. Tittarelli, C. Giosuè, S. Monosi. Combined Use of Shrinkage Reducing Admixture and $\mathrm{CaO}$ in Cement Based Materials. Mat. Sc. and Eng. 245. (2017)

2. P.K.Mehta, P.J.M. Monteiro. Concrete: Structure, Properties and Materials. s.l. : The McGraw Hill Companies, (2006). 
3. Holland, T. Using shrinkage reducing admixtures. Concrete Construction, Publication \#C99C015 Copyright@ 1999

https://www.concreteconstruction.net/ viewobject?id=00000153-8bc0-dbf3-a177-9ff9f20a0000.

4. C.M. Neubauer, H.M. Jennings and E.J. Garboczit. Mapping drying shrinkage deformations in cementbased materials. Cem. and Con. Res.10, 27,16051612, (1997)

5. D. W. Mokarem, R. E. Weyers, D. S. Lane. Development of a shrinkage performance specifications and prediction. Cem. and Con. Res. 35, 918-925, (2005)

6. J. Weiss, P. Lura, F. Rajabipour and G. Sant. Shrinkage-Reducing Admixture: Effects on Durability of High-Strength Concrete. ACI Mat. J. July-August, 110, 4, 365-374, (2013)

7. Y. Li, J. Li. Capillary tension theory for prediction of early autogenous shrinkage of self-consolidating concrete. Con. and B. Mat. 53, 511-516, (2014)

8. Bentz, D. P. Influence of Shrinkage-Reducing Admixtures on Early-Age Properties of Cement Pastes. J. of Adv. Con. Tech. . October, 4, 3, 1-7, (2006)

9. G. Sant, A. Eberhardt,D. Bentz, J. Weiss. Influence of Shrinkage-Reducing Admixtures on Moisture Absorption in Cementitious Materials at Early Ages. J. of Mat. in Civil Eng. March, 22, 3, 277-286, (2010)

10. J. Weiss, P. Lura, F. Rajabipour, G. Sant. Performance of Shrinkage-Reducing Admixtures at Different Humidities and at Early Ages. ACI Mat. J. September-October, 105, 5, 478-486, (2008)

11. E. Anastasiou, I. Papayianni. Use of calcareous fly ash in SCC. Eurocoalash. September, Thessaloniki, Greece (2012).

12. A. Liapis, E.Anastasiou, M. Papachristoforou, I. Papayanni. Feasibility study and criteria for EAF slag utilization in concrete products. J. of Sust. Metal. March 4, 1, 68-76 (2018).

13. J. Li, Y. Yao. A study on creep and drying shrinkage of high performance concrete. Cem. and Con. Res., 31, 1203-1206, (2001).

14. Haque, M. N. Strength development and drying shrinkage of high strength concretes. Cem. and Con. Comp. 18, 333-342, (1996).

15. M. Collepard, S. Biogini. Effect of water/cement ratio, pozzolanic additions and curing time on the chloride penetration. Proc. Of Int. ERMCO Conf. Stavanger., 606-615 (1989).

16. J. Liu, Z. Ou, J. Mob, Y. Wang, H. Wu. The effect of SCMs and SAP on the autogenous shrinkage and hydration process of RPC. Con. and B. Mat. November 155, 239-249 (2017) 